\title{
A conversation with Napoleone Ferrara
}

$\mathbf{N}$ apoleone Ferrara, of the University of California, San Diego, is best known for isolating and cloning vascular endothelial growth factor (VEGF). He then built the humanized monoclonal antibody against VEGF that led to the blockbuster drugs Avastin (for treating cancer) and Lucentis (for treating wet age-related macular degeneration). The full interview with Napoleone (Figure 1) can be seen on the JCI website, http://www.jci.org/videos/cgms.

JCI: Do you think you could start at the very beginning: where did you grow up?

Ferrara: I grew up in a city called Catania, which is in Sicily. We were next to Mount Etna, which is the highest volcano in Europe, and next to the beautiful Mediterranean. My mother had teaching credentials, though she really never taught, and my father was a judge. I grew up being fascinated by law. My father took me to court a number of times, and so did my uncle, who was a criminal lawyer. But probably the greatest influence on me was my maternal grandfather, who was a science teacher. I still remember his house full of books. I was so fascinated by those, and I believe I stole some of these books - even though then I returned all of them. Most of the books were on natural sciences. It was his real passion, which transmitted a little bit to me.

JCI: What led you to choose medical school?

Ferrara: At that time, at least in Italy, medical school seemed to be the most logical path even if you wanted to do true science research. For a number of years, I was not totally sure what I really wanted to do, and medical school was a great choice because it provided a biological background, which I think has been extremely helpful even in guiding my research to asking some questions which I thought to be medically and biologically relevant.

JCI: You ended up choosing to do your training in reproductive endocrinology.

Ferrara: At that time, it was exciting and cutting-edge science. I was also very much inspired by the person who I consider my first mentor, Umberto Scapagnini. He was a charismatic young professor of Pharmacology. He worked at UCSF with William Ganong, who was one of the giants of neuroendocri- nology. At the time, the University of Catania was a very good medical school, but mostly clinically oriented, and research probably was not a major focus; Scapagnini brought excitement for research. I still remember vividly his lectures explaining neurotransmitters, the hypothalamic releasing an inhibitory factor, the pituitary portal system.

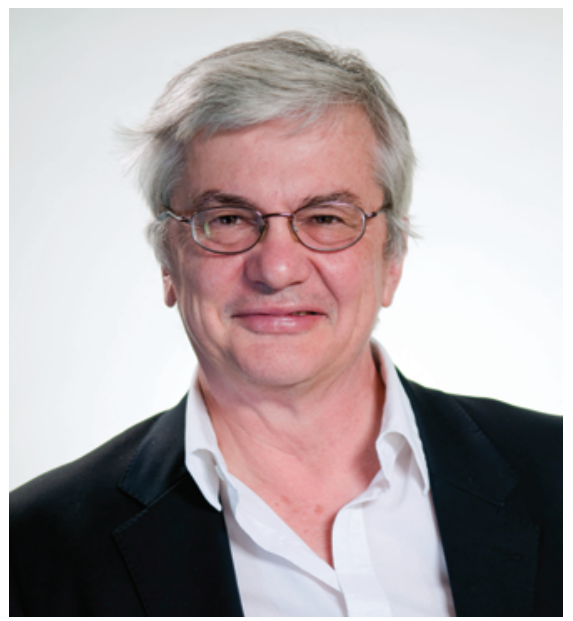

Figure 1. Napoleone Ferrara on April 26, 2014. Image credit: Karen Guth.

JCI: After your clinical training, you set sail for UCSF yourself.

Ferrara: Yes, to Richard Weiner's lab. It was a continuity of what I was doing with Scapagnini. Weiner was working in neuroendocrinology, on the pituitary gland. We were looking for something completely different, but I kind of stumbled on some cells; I was culturing bovine pituitary glands, and I came across these cells called folliculostellate cells. It took a while to identify them. They formed domes, which reflects epithelial transport. This was a very surprising thing because nobody associated pituitary cells with a transport function.

I spent countless hours trying to decipher what these cells do. In the course of the study, I had the seemingly crazy idea to test the conditioned medium of those cells on endothelial cells. There were actually some early hypotheses that suggested follicular cells could play a role in the organization of the very complex pituitary vasculature because they're frequently associated with blood vessels. To my delight, there was a very strong mitogenic effect on endothelial cells. That's what really started the VEGF story. These were the pregenomic days; to discover a factor, it was an incredibly laborious process. Fully purifying a protein could take a decade, and many people discouraged me from pursuing this story. I still persisted.

JCI: At that time did you ever consider a clinical career?

Ferrara: Combining research and clinical work would have been the logical path. Actually, I started a residency at the Oregon Health and Science University in OB-GYN in 1985, and while I appreciated the clinical work, I missed the lab a lot. So I decided to go back to UCSF to do a second research fellowship at the Cancer Research Institute in a lab that focused on growth factors. I was then very fortunate to have an opportunity to join Genentech; I understood that it was the right place to continue my work.

One of the things that I remember with the greatest fondness in those early days when I joined Genentech was that my main project was on relaxin, a hormone thought to ease the pain of childbirth, but I quickly understood that this project was very unlikely to work. My real passion was to continue the work that I began with this mysterious protein because, at that time, we didn't know what it was. All through my weekends, I tried to purify this protein. I was very fortunate to find talented collaborators. It was remarkable that in a little over six months after I joined Genentech, we were able to fully purify and determine the N-terminal amino acid sequence of VEGF from folliculostellate cells. That was probably the most exciting moment - when we compared the sequence with the database, which showed no match with any known protein.

JCI: VEGF: the sequence, the structure, the receptors. What is it about this one molecule that has enraptured you for 30 years?

Ferrara: I feel immensely fortunate that I came across this molecule because it proved to be very important, and it has been very fruitful. I always had an inclination to take risky projects, a side direction away from VEGF. But each time that I did, I realized that I was going to miss some important discovery. 
JCI: Regarding Avastin and its clinical trials, initial safety data on a phase III breast cancer trial were a little disappointing. Did you hold out hope after the very promising animal model studies?

Ferrara: It was a trial in patients with advanced breast cancer who had relapsed. In retrospect, it was a bit of a long shot to hope that this drug could do much. I think the primary end point was increasing survival in patients, but they had really advanced disease. And while it failed its primary end point, there were some very intriguing findings because there was an increase in response rate. So even though the trial did not meet its hoped-for end points, it showed there was some biological activity of this drug.

The success or failure of the Avastin program hinged on another phase III study in metastatic colorectal cancer, which was ongoing. So while we had the disappointing breast cancer news, we were all very anxiously waiting for the result of the colorectal trial.

JCI: The results from that trial showed a five-month increase in survival, and the FDA in 2004 approved the use of Avastin for colorectal carcinoma. What was your feeling on the day you got the news that it was approved?

Ferrara: It was really stunning. It was an incredible period in the face of all the negative feelings about angiogenesis. Almost everybody bet that the colorectal trial would fail. There was even a publication from a prominent group that predicted a drug that targeted only the VEGF pathway was going to fail, just like another class of drugs (matrix metalloproteinase inhibitors). So there was this gloomy sense of inevitable failure of the effort.

So it was very refreshing instead to see that this data could defy these dire predictions and validate a lot of work. I remember I learned the news from Art Levinson, who was the Genentech CEO, and he was so kind to call me. I was actually in Siena [Italy] for a week of lecturing, in this lovely city in Tuscany. I remember I drank a whole bottle of Chianti after I heard the news.

JCI: Another Genentech drug, Lucentis, has been spectacularly successful at not only treating, but also reversing the effects of wet age-related macular degeneration. How involved were you with turning attention away from tumor angiogenesis to the eye?

Ferrara: I was involved from the very beginning. It was very clear that a number of ophthalmic diseases, like ischemic retinal disease and diabetic retinopathy, were actually characterized by extensive angiogenesis. One of the earliest hypotheses postulated that an angiogenic factor called "Factor X" was important in diabetic retinopathy. The hypothesis was proposed in 1948 by one of the giants of this field, Isaac Michaelson. People had been looking for this hypothetical Factor $\mathrm{X}$ for a very long time. In the early 90s, after we cloned VEGF, there was a lot of interest in testing the possibility that VEGF might be this long-sought mediator on intraocular neovascularization, in part because it's induced by hypoxia - one of the characteristic features of ophthalmic angiogenic disease.

We developed very sensitive assays to measure VEGF and in collaboration, we were able to show that VEGF concentrations are elevated in the eye fluids of patients with ischemic retinal disease. Subsequently, we did experiments in animal models using inhibitors that we developed in the lab, which were absolutely striking. They showed that an antibody to VEGF (the same antibody that worked in the cancer models) or a chimeric soluble VEGF receptor strongly suppressed intraocular neovascularization. However, at that time, many people were concerned that these models would not be predictive. Indeed, in spite of this compelling animal data, there was a lot of skepticism, which probably delayed the decision to develop a VEGF inhibitor. Happily, there was some promising initial data, and the most compelling data came in 2005, through a phase III study with the VEGF antibody fragment (Lucentis). It was not actually in the ischemic retinal disease, which was the very initial proposed indication, but rather in wet AMD, which at that time was the leading cause of blindness. And the data were really stunning, because people at most were hoping that you could slow down the vision loss with the VEGF antibody. This trial showed that in approximately $35-40 \%$ of the patients, there was actually an increase in visual acuity. You could prevent severe visual loss in over $90 \%$ of patients. So this was really totally unexpected.

JCI: After 25 years at Genentech, you took a position as the Senior Deputy Director for Basic Science at the UCSD Moores Cancer Center. Why?

Ferrara: There are those who suggest you change jobs every 10 years. I stayed a little bit longer than that. I always had tremendous respect for academia, to the extent I was tempted before; in the mid-1990s, I strongly considered joining UCSF, but it was not the right time. But it was time, and there was this great opportunity in joining UCSD. And I think my experience at Genentech could be very helpful because it taught me how to do things with a level of rigor - for example, in developing a drug, which is something quite different from what people typically do in academia. You don't need to be directly involved in a clinical trial to help shape a new drug. After all, I was not running the Avastin or Lucentis clinical trials. It was, of course, lots of fun to discuss the clinical data. In a medical center, it's probably even easier to participate from the fringe. I'm initiating some studies with some colleagues at UCSD in cancer and eye disease; it happens that the Shiley Eye Institute is next door to the Cancer Center. So it's really a wonderful experience to be able to interact with all the clinicians and clinical investigators.

JCI: What do you see on the landscape for angiogenesis research over the next five to ten years?

Ferrara: The field has reached a level of maturity because we now know a lot about the major mediators of angiogenesis: not only on VEGF molecules, but also angiopoietins, delta 4 Notch ligand, among others. When I started working in this field, there were several potential candidates, but none had been shown to mediate physiological or pathological angiogenesis.

From a therapeutic point of view, it's been wonderful to be able to see the clinical results, which have been particularly dramatic in eye disease. There have been some very solid results in cancer too, the VEGF inhibitors representing a standard of therapy for a number of tumors. But cancer therapy is very complex. What we need is to find some effective drug combinations. For example, there is lots of promise in combining the antiangiogenic agents with immunotherapy.

JCI: Have you ever thought about pursuing another career beyond science and medicine?

Ferrara: I don't think I could do anything else. I'm interested in ancient history - classics that I read for fun, but I don't think I would've been able to make a career out of that. I think I'm very fortunate to have been able to find what I really want to do in science and research.

\section{Ushma S. Neill}

